\title{
Detección molecular de especies de Candida en especímenes de pacientes hospitalizados
}

\author{
José Luis Camacho-Cardoso', María Ángeles Martínez-Rivera', Patricia Manzano-Gayosso², \\ Luis Javier Méndez-Tovar ${ }^{3}$, Rubén López-Martínez² y Francisca Hernández-Hernández ${ }^{2}$ \\ ${ }^{1}$ Laboratorio de Micología Médica, Departamento de Microbiología, Escuela Nacional de Ciencias Biológicas, Instituto Politécnico Nacional; \\ ${ }^{2}$ Departamento de Microbiología y Parasitología, Facultad de Medicina, Universidad Nacional Autónoma de México; ${ }^{3}$ Hospital de Especialidades, \\ Centro Médico Nacional Siglo XXI, Instituto Mexicano del Seguro Social. Ciudad de México, México
}

\section{Resumen}

Objetivo: Detectar las especies de Candida más frecuentes en especímenes de pacientes hospitalizados en diferentes centros médicos de la Ciudad de México, con sospecha de infección fúngica. Métodos: Los especímenes fueron cultivados en agar dextrosa Sabouraud a $28{ }^{\circ} \mathrm{C}$ por 72 horas. Además, se realizó extracción de ADN. Los aislados fueron cultivados en CHROMagar Candida ${ }^{T M}$ a $37^{\circ} \mathrm{C}$ por 72 horas. La identificación molecular se efectuó mediante reacción en cadena de la polimerasa (PCR), utilizando iniciadores específicos para cuatro especies. Resultados: Se procesaron 81 especímenes que incluyeron líquidos de lavado bronquial, pleural, cefalorraquídeo, peritoneal, ascitis y biliar; sangre, esputo, médula ósea, cánula orotraqueal y ganglio. Por cultivo, 30 (37\%) muestras fueron positivas, y por PCR, 41 (50.6\%). Por PCR, la frecuencia de especies detectadas fue C. albicans $82.9 \%$, C. tropicalis $31.7 \%$, C. glabrata $24.4 \%$ y C. parapsilosis $4.9 \%$. En el $34.1 \%$ de los especímenes se detectó mezcla de especies, indicando coinfección: dos especies en cinco especímenes (C. albicans-C. tropicalis y C. albicans-C. glabrata) y tres especies en tres especímenes (C. albicans-C. glabrata-C. tropicalis). Conclusiones: La PCR es una herramienta útil para detectar las especies de Candida comúnmente causantes de infección en pacientes hospitalizados, no requiere cultivo si se parte directamente del espécimen clínico y favorece el diagnóstico temprano de candidiasis invasiva.

PALABRAS CLAVE: Candida albicans. Candida tropicalis. Candida glabrata. Candida spp. Candidiasis invasiva. Reacción en cadena de la polimerasa. CHROMagar Candida ${ }^{T M}$.

\begin{abstract}
Objective: To identify the most frequent Candida species in specimens from patients hospitalized in different medical centers of Mexico City, with suspected fungal infection. Methods: Specimens were grown on Sabouraud dextrose agar at $28^{\circ} \mathrm{C}$ for $72 \mathrm{~h}$. In addition, DNA was extracted. Isolates were grown on CHROMagar Candida ${ }^{T M}$, at $37^{\circ} \mathrm{C}$ for $48 \mathrm{~h}$. The molecular identification was performed by polymerase chain reaction $(P C R)$ using primers specific for four species. Results: Eighty one specimens were processed and included: bronchial lavage, pleural, cerebrospinal, peritoneal, ascites and bile fluids; blood, sputum, bone marrow, oro-tracheal cannula and ganglion. By culture, 30 samples (37\%) were positive, and by PCR, 41 (50.6\%). By PCR, the frequency of species was: Candida albicans $82.9 \%$, Candida tropicalis $31.7 \%$, Candida glabrata $24.4 \%$, and Candida parapsilosis $4.9 \%$. In $34.1 \%$ of specimens a species mixture was detected suggesting a co-infection: Two species in five specimens (C. albicans- $C$ tropicalis and $C$. albicans-C glabrata), and three species in three specimens (C. albicans- $C$. glabrata-C. tropicalis). Conclusions: The PCR is an useful tool for detection the most common Candida species causing in-
\end{abstract}

\author{
Correspondencia: \\ Francisca Hernández-Hernández \\ Facultad de Medicina \\ Av. Universidad, No. 3000 \\ Col. Universidad Nacional Autónoma de México, C. U. \\ Del. Coyoacán \\ Fecha de recepción: 06-04-2016 \\ C.P. 04510, Ciudad de México, México Fecha de aceptación: 07-04-2016 \\ E-mail: frank-hh@comunidad.unam.mx DOI:10.24875/GMM.17002535

Gac Med Mex. 2017; 153:581-589
Contents available at PubMed
www.gacetamedicademexico.com 
fection in hospitalized patients, it avoids the requirement of culture weather we start from clinical specimen and it favors the early diagnosis of invasive candidiasis.

KEY WORDS: Candida albicans. Candida tropicalis. Candida glabrata. Candida spp. Invasive candidiasis. Polimerase chain reaction. CHROMagar Candida ${ }^{T M}$.

\section{Introducción}

El género Candida está constituido por diversas especies potencialmente causantes de candidiasis, una micosis de expresión clínica variable (infección superficial, mucocutánea e invasiva) cuya frecuencia ha aumentado en las tres últimas décadas debido al incremento de los factores de riesgo en los pacientes inmunocomprometidos ${ }^{1-4}$.

La candidiasis invasiva es la infección nosocomial de origen fúngico más importante por su frecuencia y gravedad, con índices de letalidad $\geq 40 \%$. Los principales factores de oportunismo ligados a esta infección incluyen la diabetes mellitus, la infección por el virus de la inmunodeficiencia humana $(\mathrm{VIH})$-sida, la fiebre asociada a neutropenia, las neoplasias, la instalación prolongada de catéteres venosos o urinarios, las válvulas cardíacas, el uso prolongado de esteroides, de antibióticos de amplio espectro y de inmunosupresores, la cirugía y el trasplante de órganos sólidos ${ }^{2,4-7}$.

Entre las más de 150 especies de Candida descritas, solo alrededor de 15 han sido aisladas de pacientes como agentes de infección ${ }^{8}$. Candida albicans permanece como el agente más común de infecciones nosocomiales, seguido de Candida tropicalis, Candida parapsiIosis, Candida glabrata y Candida krusei. La importancia de identificar las especies fúngicas involucradas en la infección radica en que algunas de ellas presentan resistencia innata a algunos antifúngicos ${ }^{4,6,7,9,10}$.

El diagnóstico de la candidiasis invasiva es difícil debido a que los signos y síntomas son inespecíficos, así como al hecho de que estas levaduras oportunistas son comensales principalmente de las mucosas en el humano ${ }^{11}$. En el laboratorio clínico, los procedimientos convencionales para realizar el diagnóstico de la candidiasis invasiva incluyen estudios morfológicos y bioquímicos, como el frotis, el cultivo, la histopatología, la serología y, en ocasiones, el uso de anticuerpos fluorescentes específicos ${ }^{1,3,12-14}$. Sin embargo, la sensibilidad y la especificidad de estos métodos son bajas. En los pacientes neutropénicos se detectan levaduras por cultivo o por histopatología aproximadamente a los 120-140 días posteriores a la detección de este factor predisponente, lo cual induce una terapia específica tardía ${ }^{11}$. Para algunos autores, el cultivo es el método de referencia para el diagnóstico de la candidiasis invasiva ${ }^{15}$. Con el objetivo de lograr un diagnóstico más rápido y específico para establecer una terapia exitosa, en los últimos años se han desarrollado y aplicado los procedimientos moleculares, como la reacción en cadena de la polimerasa (PCR, polymerase chain reaction) y sus variantes, cuyos resultados superan a los procedimientos convencionales en tiempo, sensibilidad y especificidad ${ }^{9,12,16,17}$. Recientemente, la espectrometría de masas ha surgido como una técnica de laboratorio rápida y confiable, que puede utilizarse como un procedimiento alternativo para la identificación de hongos ${ }^{10,14,18}$.

En México existen pocos estudios que reportan la frecuencia de aislamiento de las especies de Candida en muestras clínicas, y aún son más escasos estos reportes en los centros hospitalarios de la Ciudad de México. Las principales especies de Candida asociadas a infecciones invasivas son $C$. albicans, $C$. tropicalis, C. glabrata y C. parapsilosis. El objetivo de este trabajo fue detectar las cuatro especies de Candida más relevantes directamente en especímenes clínicos procedentes de pacientes hospitalizados en diferentes centros de la Ciudad de México con sospecha de infección fúngica, y así contribuir al diagnóstico temprano de candidiasis invasiva.

\section{Métodos}

Se solicitaron especímenes biológicos a diferentes centros hospitalarios de la ciudad de México, provenientes de pacientes hospitalizados, con uno o más factores de oportunismo, sospecha clínica de micosis invasiva o diagnóstico no determinado asociado a fiebre de origen desconocido. Se recibieron y procesaron 81 muestras del Laboratorio Central correspondiente: 11 del Hospital de Infectología del Centro Médico La Raza del Instituto Mexicano del Seguro Social (IMSS); 20 del Hospital Regional General Ignacio Zaragoza, del Instituto de Seguridad y Servicios Sociales para los Trabajadores del Estado (ISSSTE); 28 del Hospital de Especialidades del Centro Médico Nacional Siglo XXI del IMSS; una del Hospital General Dr. Darío Fernández Fierro del 
ISSSTE; y 21 del Hospital General de México Dr. Eduardo Liceaga de la Secretaría de Salud.

Todas las muestras clínicas fueron cultivadas en agar dextrosa Sabouraud (ADS) sin antibióticos, incubadas a $28^{\circ} \mathrm{C}$ por 72 horas. Se registró el número de unidades formadoras de colonias (UFC). Los cultivos de esputo que presentaron crecimiento levaduriforme fueron considerados positivos cuando tuvieron un número $\geq 1 \times 10^{4}$ UFC. Para las muestras estériles se consideró positivo cualquier crecimiento levaduriforme. Los cultivos positivos en ADS fueron resembrados en CHROMagar Candida ${ }^{\text {TM }} \mathrm{e}$ incubados por 72 horas a $37^{\circ} \mathrm{C}$ en oscuridad, con la finalidad de establecer la identificación presuntiva de la especie o especies involucradas en el proceso infeccioso, de acuerdo con el color de la colonia; para estos aislados no fue necesario efectuar la extracción de ADN.

Como cepas de referencia se incluyeron $C$. albicans ATCC 64550, C. glabrata ATCC 90030, C. tropicalis ATCC 750 y C. parapsilosis ATCC 29019. Estas cepas fueron sembradas en medio extracto de levadura (YPD, yeast extract peptone dextrose) e incubadas por 48 horas a $37^{\circ} \mathrm{C}$. Se realizó la extracción de ADN utilizando el método de Blin y Stanford ${ }^{19}$. El ADN fue tratado con RNAsa A (10 $\mu \mathrm{g} / \mathrm{ml}$, Invitrogen $\left.{ }^{\circledR}\right)$ de acuerdo con las instrucciones del fabricante, y purificado, re-suspendido en agua desionizada estéril y cuantificado por espectrofotometría. El ADN de estas cepas de referencia fue utilizado solamente para estandarizar la técnica de PCR.

Para la extracción de ADN de sangre total se siguió el procedimiento recomendado por Loffler, et $\mathrm{al}^{20}$. A $1 \mathrm{ml}$ de sangre total se adicionó $1 \mathrm{ml}$ de regulador de lisis

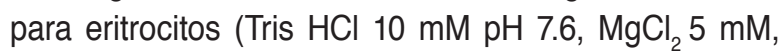
$\mathrm{NaCl} 10 \mathrm{mM}$ ) y la mezcla se incubó en hielo durante 15 minutos. Se centrifugó a 13,000 g por 15 minutos. Al sedimento se le adicionó $1 \mathrm{ml}$ de regulador de lisis para leucocitos (Tris $\mathrm{HCl} 10 \mathrm{mM}$ pH 7.6, EDTA $10 \mathrm{mM}, \mathrm{NaCl}$ $50 \mathrm{mM}$, SDS $0.2 \%$ ) y proteinasa $\mathrm{K}$ (concentración final $200 \mu \mathrm{g} / \mu \mathrm{l})$. La mezcla fue incubada a $65^{\circ} \mathrm{C}$ por $60 \mathrm{mi}-$ nutos. Se centrifugó a $13,000 \mathrm{~g}$ por 15 minutos. Se descartó el sobrenadante y se utilizó el sedimento para la extracción de ADN usando el QIAamp DNA mini kit.

Para la extracción de ADN de otros líquidos corporales se siguió el procedimiento de Loffler, et al. ${ }^{20}$. Se centrifugó $1 \mathrm{ml}$ de muestra a $13,000 \mathrm{~g}$ por 5 minutos. El sedimento fue recuperado y se le adicionaron $650 \mu \mathrm{l}$ de solución de liticasa (150 U de liticasa en Tris $\mathrm{HCl}$ $50 \mathrm{mM} \mathrm{pH}$ 7.5, EDTA $10 \mathrm{mM} \mathrm{pH} 7.8$ y $\beta$ mercaptoetanol $28 \mathrm{mM})$. La mezcla fue incubada a $37{ }^{\circ} \mathrm{C}$ por 45 minutos y centrifugada a $13,000 \mathrm{~g}$ por 15 minutos. El sedimento fue resuspendido en buffer TE, y el ADN se extrajo con el QIAamp DNA mini kit, siguiendo las instrucciones del fabricante. El ADN fue almacenado a $-20^{\circ} \mathrm{C}$ hasta su utilización para la PCR.

EI ADN obtenido tanto de las cepas de referencia (para la estandarización de la PCR) como de los especímenes clínicos (para la detección de especies de Candida) fue utilizado para realizar el ensayo de PCR con los iniciadores específicos para cada especie, según Luo y Mitchell ${ }^{16}$ (Tabla 1).

De acuerdo con las condiciones propuestas por Luo y Mitchell ${ }^{16}$, la mezcla de reacción contenía $1 \mathrm{ng}$ de ADN, MgCl $1.5 \mathrm{mM}$, dNTPs $0.2 \mathrm{mM}$, oligonucleótidos $0.5 \mu \mathrm{M}$ y Taq polimerasa $0.5 \mathrm{U}$. Las condiciones de amplificación consistieron en desnaturalización inicial a $96{ }^{\circ} \mathrm{C}$ por 5 minutos; 40 ciclos de desnaturalización a $94^{\circ} \mathrm{C}$ por 30 segundos; alineamiento a $58^{\circ} \mathrm{C}$ por 30 segundos; y polimerización a $72{ }^{\circ} \mathrm{C}$ por 30 segundos. Se propició una extensión final a $72^{\circ} \mathrm{C}$ por 15 minutos. Los amplicones fueron separados por electroforesis en gel de agarosa al 1.5\%, teñido con bromuro de etidio. Previa estandarización con las cepas de referencia, la especie de Candida se determinó de acuerdo con el tamaño del amplicón obtenido (Tabla 1).

A partir de un cultivo de C. albicans, C. tropicalis, C. glabrata y C. parapsilosis de 24 horas en ADS, se preparó una suspensión y se adicionó a $500 \mu$ de sangre total/EDTA obtenida de un individuo sano, de tal forma que la cantidad de levaduras para determinar la sensibilidad de la PCR en este producto biológico fuera de 5, 10, 50, 100 y 500 células en $500 \mu \mathrm{l}$. Esta mezcla fue procesada para la extracción de ADN y para la PCR siguiendo los procedimientos descritos previamente. El límite inferior de detección de ADN utilizando las diferentes cantidades de levaduras en muestras de sangre total fue de 100 células $/ 500 \mu \mathrm{l}$ para cada una de las cuatro especies.

\section{Resultados}

En la figura 1 se muestran los productos de amplificación obtenidos con el ADN de las cuatro especies de Candida de referencia, utilizando los iniciadores específicos de especie. El tamaño de los amplicones observado fue igual al esperado.

Las 81 muestras clínicas procesadas pertenecían a adultos de entre 20 y 70 años, el $64.5 \%$ hombres y el $35.5 \%$ mujeres, e incluyeron 25 líquido de lavado bronquial (LLB), 19 de sangre, 15 de esputo, 7 líquido pleural, 3 líquido peritoneal, 3 líquido de ascitis, 2 líquido cefalorraquídeo, 2 orina, 1 líquido de vesícula biliar, 1 secreción de úlcera, 1 médula ósea, 1 cánula 
Gaceta Médica de México. 2017;153

Tabla 1. Iniciadores utilizados para amplificar la región ITS1/ITS2 de especies de Candida ${ }^{16}$

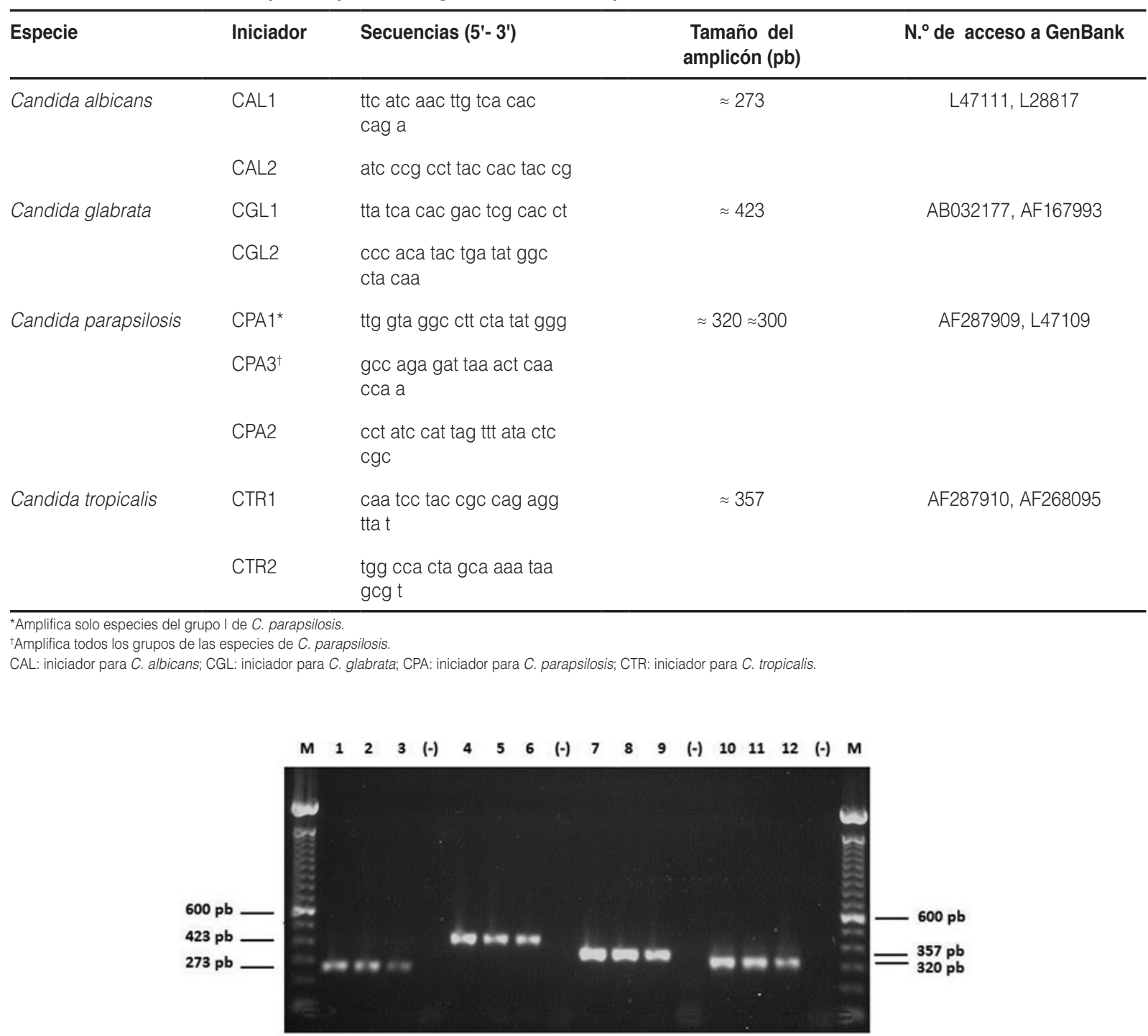

Figura 1. Productos de amplificación de las regiones ITS 1 e ITS2 de las cepas de referencia (C. albicans, carriles 1-3; C. glabrata, carriles 4-6; C. tropicalis, carriles 7-9; y C. parapsilosis, carriles 10-12). Se utilizaron 100, 10 y $1 \mathrm{ng}$ de ADN total para cada especie. M: marcador de $100 \mathrm{pb}$. $(-)$ : controles negativos.

orotraqueal y 1 ganglio. La mayoría de los pacientes (67.5\%) tenía como diagnóstico neumonía, una minoría tuberculosis pulmonar (6.1\%) y el resto otros diagnósticos. De las 19 muestras de sangre, 17 correspondían a pacientes con diagnóstico de fiebre de origen desconocido. Considerando los tres productos biológicos mayoritarios, de las 25 muestras de LLB, 19 de sangre total y 15 de esputo, 20 (80\%), 3 (15.7\%) y $14(93.3 \%)$, respectivamente, resultaron positivas por cultivo o $\mathrm{PCR}$ (o por ambos métodos).

En la tabla 2 se muestra el resultado comparativo de las muestras que fueron positivas por cultivo y por PCR de los LLB, y en la tabla 3 puede verse el resultado correspondiente de otros líquidos corporales. De las 81 muestras, $30(37 \%)$ resultaron positivas por cultivo en ADS para Candida spp., y un cultivo correspondió a Cryptococcus sp.

De los cultivos en CHROMagar Candida ${ }^{\mathrm{TM}}$, la especie que con mayor frecuencia se aisló fue $C$. albicans (24/30, $80 \%)$, seguida de C. glabrata y C. tropicalis (4/30,13.3\% para cada una). En este medio no se identificó C. parapsilosis. En tres casos (10\%) se identificó asociación de dos especies: uno de $C$. tropicalis con $C$. krusei y dos de $C$. albicans con $C$. tropicalis.

Por PCR se detectaron 41 (50.6\%) muestras positivas para Candida spp. La especie más frecuente fue C. albicans (82.9\%), seguida de C. tropicalis (31.7\%), C. glabrata (24.4\%) y C. parapsilosis (4.9\%). En 14 
Tabla 2. Detección de Candida spp. en el líquido de lavado bronquial procesado por cultivo y PCR específica de especie

\begin{tabular}{|c|c|c|c|c|}
\hline Muestra & Diagnóstico previo & Cultivo en ADS & Cultivo en CHROMagar Candida ${ }^{\mathrm{TM}}$ & PCR específica de especie \\
\hline LLB 08-193 & Neumonía & Negativo & Negativo & C. albicans \\
\hline 170 & Neumonía & Positivo & C. albicans & C. albicans \\
\hline 105 & EVC & Positivo & C. glabrata & $\begin{array}{l}\text { C. albicans, } \\
\text { C. glabrata }\end{array}$ \\
\hline 08-275 & Micosis pulmonar & Positivo & C. tropicalis & C. tropicalis \\
\hline 628-08 & Neumonía & Negativo & Negativo & C. albicans \\
\hline 416 & Neumonía & Positivo & C. albicans & C. albicans \\
\hline 485-08 & Neumonía & Negativo & Negativo & $\begin{array}{l}\text { C. albicans, } \\
\text { C. glabrata, } \\
\text { C. tropicalis }\end{array}$ \\
\hline 74 & Neumonía & Negativo & Negativo & C. tropicalis \\
\hline 1981 & Neumonía & Negativo & Negativo & C. albicans \\
\hline 43 & Neumonía & Positivo & C. albicans & $\begin{array}{l}\text { C. albicans, } \\
\text { C. tropicalis }\end{array}$ \\
\hline 676-08 & Neumonía & Positivo & C. albicans & $\begin{array}{l}\text { C. albicans, } \\
\text { C. glabrata }\end{array}$ \\
\hline 1979 & Neumonía & Negativo & Negativo & $\begin{array}{l}\text { C. albicans, } \\
\text { C. glabrata }\end{array}$ \\
\hline 101 & EVC & Positivo & C. albicans & C. albicans \\
\hline 511 & Neumonía & Positivo & C. albicans & $\begin{array}{l}\text { C. albicans, } \\
\text { C. tropicalis }\end{array}$ \\
\hline $1012-08$ & Neumonía & Positivo & C. albicans & C. albicans \\
\hline 08-512 & TR, neumonía & Negativo & Negativo & C. albicans \\
\hline 08-505 & $\mathrm{VIH} /$ micosis & Positivo & C. albicans & C. glabrata \\
\hline C108 & Neumonía & Positivo & C. albicans & C. albicans \\
\hline C23 & Neumonía & Positivo & C. albicans & C. albicans \\
\hline 81 & Neumonía & Positivo & C. glabrata & C. glabrata \\
\hline
\end{tabular}

ADS: agar dextrosa Sabouraud; LLB: líquido de lavado bronquial; EVC: enfermedad vascular cerebral; PCR: reacción en cadena de la polimerasa; TR: trasplante renal; VIH: virus de la inmunodeficiencia humana.

casos $(34.1 \%)$ se evidenciaron dos o tres especies. Las mezclas predominantes de dos especies fueron: cinco casos de $C$. albicans con $C$. tropicalis y tres casos de $C$. albicans con $C$ glabrata. Respecto a la mezcla de tres especies, predominaron C. albicans, C. glabrata y C. tropicalis, en tres casos.

Comparando los resultados obtenidos para la identificación de especies de Candida por cultivo en CHROMagar Candida ${ }^{\mathrm{TM}}$ y por PCR, el cultivo mostró en total 12 falsos negativos. Cuando en este medio se identificó una especie, esta también se detectó por PCR. Por cultivo en CHROMagar Candida ${ }^{\mathrm{TM}}$ se observó asociación de dos especies en tres casos, y por PCR la asociación de dos o tres especies se encontró en 14 casos. Estos resultados evidencian las mayores sensibilidad, especificidad y rapidez de la técnica de PCR al compararla con el cultivo en CHROMagar Candida ${ }^{\mathrm{TM}}$.

En la figura 2 se muestran algunos productos amplificados de las cuatro especies de Candida obtenidos a partir de muestras clínicas con los iniciadores específicos para Candida spp.

Una muestra de esputo fue positiva por cultivo en ADS, identificada como C. glabrata en CHROMagar Candida $^{\mathrm{TM}}$ y negativa por PCR.

La figura 3 presenta los resultados obtenidos por cultivo y por PCR para cada una de las especies de Candida. La diferencia de positividad de cada procedimiento está directamente relacionada con la frecuencia con que se identificaron las cuatro especies. 


\section{Discusión}

Las infecciones por Candida spp. son causa de gran morbilidad y mortalidad en pacientes con algún factor de oportunismo asociado, por lo que su diagnóstico debe ser rápido y confiable para establecer un tratamiento eficaz y oportuno.

Actualmente, algunos autores consideran el cultivo como método de referencia para el diagnóstico de candidiasis invasiva, en particular a partir de muestras estériles ${ }^{15}$. Para otros autores este procedimiento no es totalmente confiable, debido a que, tratándose de muestras sanguíneas, hasta el $50 \%$ de ellas son negativas y el tiempo en que se obtiene el resultado es de 3 días o más ${ }^{9,12,14}$. Los procedimientos moleculares han mostrado ser más rápidos, sensibles, específicos y confiables que los métodos fenotípicos ${ }^{17,18}$. En el presente trabajo se utilizó la PCR específica para determinar la frecuencia de las cuatro especies de Candida reportadas como más comunes que afectan a los pacientes hospitalizados por diversas causas.

Considerando el origen de las muestras, el porcentaje de positividad más alto, tanto por cultivo como por PCR (93.3\%), correspondió al esputo, único producto no estéril procesado en este estudio. La mayoría de los pacientes de quienes provenían estas muestras tenían un diagnóstico previo de infección (neumonía, absceso pulmonar, tuberculosis o infección por $\mathrm{VIH}$ ), por lo que basados en el número elevado de levaduras detectadas por cultivo en ADS consideramos que un alto número de ellos tenía una franca infección por Candida.

Las muestras de LLB mostraron una mayor positividad por la PCR $(80 \%)$ que por el cultivo en ADS (52\%). Esta diferencia podría atribuirse parcialmente a que la respuesta inmunitaria específica o inespecífica del hospedero podría ejercer un efecto fungicida o fungistático sobre las levaduras, lo cual impediría su desarrollo. Schabereiter-Gurtner, et al. ${ }^{21}$, encontraron un $19.4 \%$ de

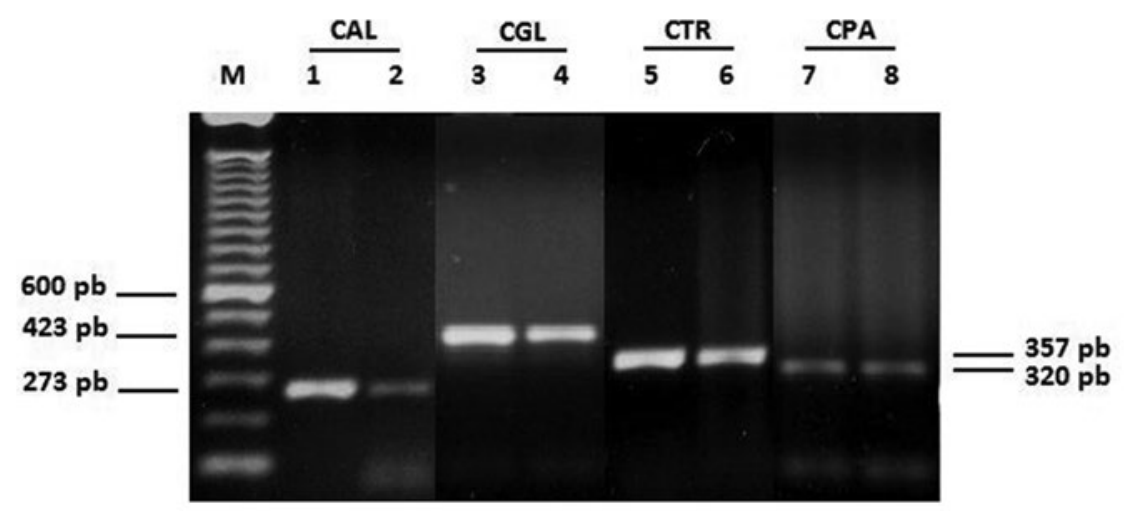

Figura 2. Productos de amplificación de las regiones ITS 1 e ITS2 de las cuatro especies de Candida recuperadas de muestras clínicas. M: marcador de 100 pb. Carril 1: 511; carril 2: 08-512; carril 3: C11; carril 4: 2719; carril 5: 485-08; carril 6: 08-505; carril 7: 1151-08; carril 8: 512.

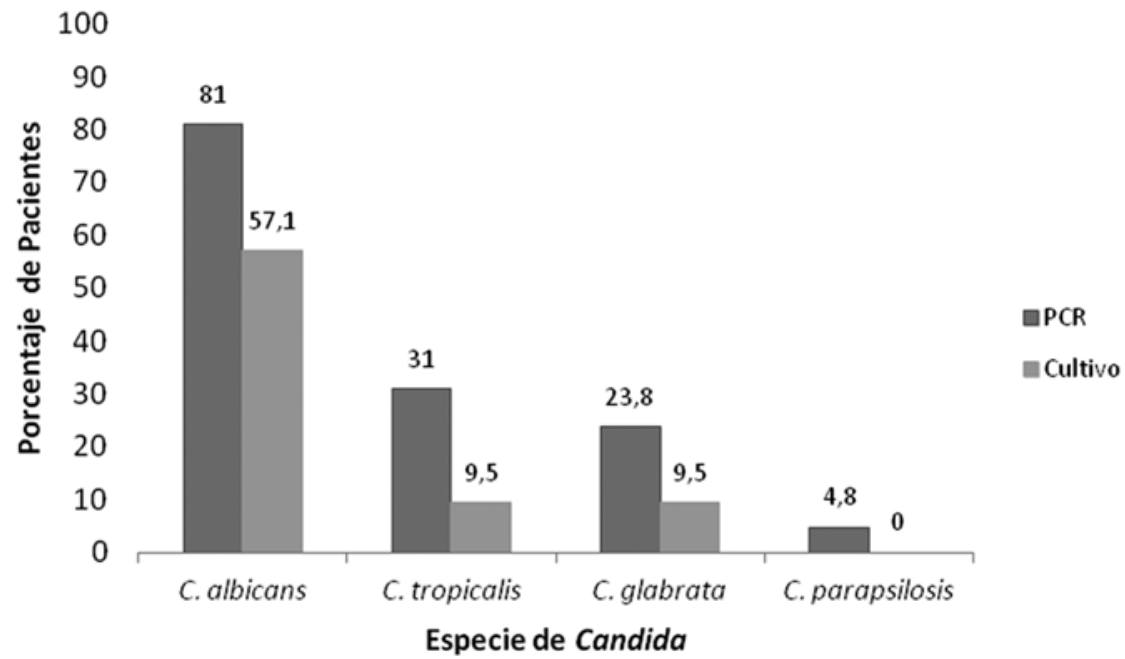

Figura 3. Correlación entre el resultado de la PCR y del cultivo para la detección de cada una de las cuatro especies de Candida $(n=81)$. 
Tabla 3. Detección de Candida spp. en diversas muestras por cultivo y PCR específica de especie

\begin{tabular}{|c|c|c|c|c|}
\hline Muestra & Diagnóstico previo & $\begin{array}{l}\text { Cultivo en } \\
\text { ADS }\end{array}$ & Cultivo en CHROMagar Candida ${ }^{\mathrm{TM}}$ & $\begin{array}{l}\text { PCR específica de } \\
\text { especie }\end{array}$ \\
\hline Esputo 171 & Neumonía & Positivo & C. albicans & C. albicans \\
\hline 188 & AP & Positivo & C. glabrata & C. glabrata, C. tropicalis \\
\hline 248 & $\mathrm{~Tb}$ & Positivo & C. albicans & C. albicans \\
\hline 496-08 & Neumonía & Positivo & C. albicans & C. albicans, C. tropicalis \\
\hline $617-08$ & Neumonía & Positivo & C. albicans & C. albicans \\
\hline 459 & $\mathrm{~Tb}$ & Positivo & C. albicans & C. albicans \\
\hline 460 & $\mathrm{VIH}$ & Positivo & C. albicans & C. albicans \\
\hline 426 & $\mathrm{VIH}$ & Positivo & C. albicans & C. albicans \\
\hline $656-08$ & Neumonía & Positivo & C. albicans & C. albicans \\
\hline 519 & Neumonía & Positivo & $\begin{array}{l}\text { C. tropicalis, } \\
\text { C. krusei }\end{array}$ & $\begin{array}{l}\text { C. glabrata, C. tropicalis, } \\
\text { C. parapsilosis }\end{array}$ \\
\hline 543 & Neumonía & Positivo & C. albicans & C. albicans, C. tropicalis \\
\hline 2719 & Neumonía & Positivo & $\begin{array}{l}\text { C. albicans, } \\
\text { C. tropicalis }\end{array}$ & $\begin{array}{l}\text { C. albicans, C. glabrata, } \\
\text { C. tropicalis }\end{array}$ \\
\hline $1151-08$ & Neumonía & Positivo & C. albicans & C. albicans, C. parapsilosis \\
\hline 289 & $\mathrm{~Tb}$ & Positivo & C. glabrata & Negativo \\
\hline Sangre C547 & FOD & Negativo & Negativo & C. albicans \\
\hline 19 & FOD & Negativo & Negativo & C. albicans \\
\hline 23 & FOD & Negativo & Negativo & C. albicans \\
\hline Orina $536-08$ & ND & Positivo & C. albicans & C. albicans \\
\hline C11 & ND & Positivo & $\begin{array}{l}\text { C. albicans } \\
\text { C. tropicalis }\end{array}$ & $\begin{array}{l}\text { C. albicans, C. tropicalis, } \\
\text { C. glabrata }\end{array}$ \\
\hline Líquido pleural 662 & Enteropatía, Neumonía & Negativo & Negativo & C. albicans \\
\hline Bilis 2508 & Septicemia & Positivo & C. albicans & C. albicans, C. tropicalis \\
\hline Ganglio 825 & $\mathrm{VIH}, \mathrm{Tb}$ & Negativo & Negativo & C. tropicalis \\
\hline LCR & Meningitis & Positivo & $N D^{*}$ & Negativo \\
\hline
\end{tabular}

*En el examen microscópico con tinta china se observaron levaduras redondas, capsuladas.

ADS: agar dextrosa Sabouraud; AP: absceso pulmonar; FOD: fiebre de origen desconocido; LCR: líquido cefalorraquídeo; ND: no determinado; PCR: reacción en cadena de la polimerasa; Tb: tuberculosis; VIH: virus de la inmunodeficiencia humana.

falsos negativos en cultivos de diferentes especímenes para Candida spp. y Aspergillus spp. en comparación con la PCR en tiempo real. El tratamiento con antifúngicos previo a la toma de muestras podría tener también un efecto directo en la inhibición del crecimiento de las levaduras ${ }^{17,22}$.

Las 19 muestras de sangre fueron negativas por cultivo en ADS y presentaron un bajo porcentaje de positividad por PCR (15.7\%). Los falsos negativos han sido atribuidos a sustancias inhibidoras de la PCR, como la hemoglobina y la lactoferrina, comúnmente asociadas a los eritrocitos y los leucocitos, respectivamente $^{23}$. En contraste con nuestros resultados, varios autores han encontrado que la positividad del hemocultivo oscila entre el 50 y el $60 \%$ de los $\operatorname{casos}^{24}$. En un estudio de pacientes con fiebre de origen desconocido, Méndez, et al. ${ }^{25}$ encontraron que el $35 \%$ cursaban con alguna infección fúngica, principalmente candidiasis, por lo que es necesario considerar este tipo de infecciones en el diagnóstico presuntivo.

Las dos muestras de orina procesadas fueron positivas por cultivo en ADS y por PCR. Aunque la candiduria no es un indicador específico de candidiasis, ha sido propuesta como un indicador de mal pronóstico en pacientes de edad avanzada, como consecuencia de otras enfermedades asociadas. Los urocultivos positivos de los 
pacientes graves (estancia prolongada en la unidad de cuidados intensivos, prematuros, pacientes con quemaduras o receptores de trasplante) son particularmente importantes, porque pueden preceder a una candidemia o ser indicio de una candidiasis renal grave ${ }^{12,24}$.

Respecto a la distribución de especies por ambos métodos, se detectó con mayor frecuencia $C$. albicans, seguida de C. tropicalis y $C$. glabrata. Esta frecuencia es igual a la reportada por otros autores mexicanos que han realizado una metodología similar ${ }^{9}$. En un estudio llevado a cabo por Hernández, et al. ${ }^{26}$, a partir de diferentes productos biológicos y utilizando métodos fenotípicos, se reportó una frecuencia de aislamiento de $C$. albicans del 68.6\%, seguida de C. parapsilosis $(8.6 \%)^{26}$. En un estudio de vigilancia de 3 años (2004-2007) con aislados de Candida spp. obtenidos de pacientes de cinco centros hospitalarios de Monterrey (México), y utilizando estudios fenotípicos, González, et al. ${ }^{27}$ reportaron $C$. parapsilosis como la especie más frecuente $(37.9 \%)$ aislada de sangre, seguida de C. albicans (31.9\%), C. tropicalis (14.8\%) y C. glabrata (8\%), principalmente en población pediátrica portadora de catéteres. Este trabajo incluyó solo población adulta, y $C$. parapsilosis se identificó en un bajo porcentaje únicamente por PCR (4.9\%), ya que es una especie que no se identifica por cultivo en CHROMagar Candida ${ }^{\mathrm{TM}}$.

El CHROMagar Candida ${ }^{\mathrm{TM}}$ es una técnica sencilla y relativamente económica en el laboratorio de diagnóstico micológico. Tiene como ventaja que detecta mezclas de especies y proporciona, en un máximo de 72 horas, la identificación presuntiva de algunas especies de Candida (C. albicans, C. glabrata, C. tropicalis y $C$. krusei $)^{9,13}$. En este trabajo, solo en tres casos (10\%) se detectó mezcla de especies en este medio.

La PCR fue notablemente superior en la detección de mezcla de especies (34.1\%) respecto al CHROMagar Candida ${ }^{\mathrm{TM}}$. Se detectaron asociaciones de dos y tres especies en la misma muestra biológica. La detección de coinfecciones por dos o más especies en muestras clínicas también ha sido reportada por otros autores $^{28-30}$. La detección de mezclas es útil para la elección de un tratamiento adecuado, ya que una o más especies podrían ser resistentes a uno o más antifúngicos, lo cual podría conducir a la administración de una terapia inapropiada y con ello favorecer la selectividad de resistencia y la diseminación de los agentes etiológicos ${ }^{13,14}$. Actualmente la PCR es una herramienta también útil para la detección de cepas resistentes a los antifúngicos de uso terapéutico ${ }^{9,14,18}$.

C. albicans es la especie predominante como agente causal de candidiasis. Este microorganismo representa un serio problema de salud pública con relevancia clínica, debido a su alta tasa de morbimortalidad $2,4,7,30$. Es relevante, además de su alta frecuencia, porque en los últimos años se ha detectado un incremento en la aparición de cepas resistentes a los compuestos azólicos ${ }^{15,31,32}$.

En los EE.UU., C. tropicalis es la cuarta especie causante de candidiasis sistémica, mientras que en Latinoamérica es la segunda ${ }^{4,6}$. Existen reportes que refieren que $C$. tropicalis adquiere rápidamente resistencia durante la terapia con azoles ${ }^{21}$.

Se sabe que C. glabrata presenta resistencia intrínseca al fluconazol y resistencia cruzada a otros azoles ${ }^{4,13,24}$. Esta especie frecuentemente causa infecciones en pacientes bajo terapia profiláctica con azoles ${ }^{6,27,30}$.

Aunque $C$. parapsilosis es un patógeno exógeno que se ha encontrado en la piel normal, esta especie está involucrada en infecciones sistémicas, en particular en neonatos ${ }^{7,24}$. En América Latina, C. parapsilosis se ha encontrado en pacientes de todas las edades ${ }^{4}$. En menor proporción que otras especies, C. parapsilosis también ha desarrollado resistencia a compuestos azólicos de uso común en la terapia antifúngica ${ }^{31}$.

De los métodos actuales para establecer el diagnóstico de candidiasis invasiva, la Food and Drugs Administration de los EE.UU. ha aprobado cuatro:

- MALDI-TOF (Matrix Assisted Laser Desorption/lonization Time-Of-Flight) es un procedimiento que utiliza espectroscopía de masas y requiere un cultivo puro de levadura que puede necesitar de 24 a 48 horas. Después de este tiempo, el resultado puede conocerse en 10-15 minutos, con la ventaja de conocer la mayoría de las especies de Candida.

- PNA-FISH (Peptide Nucleic Acid Fluorescent In Situ Hybridization) requiere un cultivo no necesariamente puro, y solo aporta dos resultados pareados: C. albicans/C. tropicalis y C. glabrata/C. kruseilC. parapsilosis (no da información para una sola especie). Existe en forma de kit comercial.

- La prueba de $\beta$-D-glucano detecta este componente de la pared fúngica en sangre, por lo que es una prueba panfúngica (Candida spp., Aspergillus spp., Pneumocystis jirovecii, hongos dematiáceos y varios más). Requiere dos resultados positivos para confirmarse. Es una prueba inespecífica, cara y tediosa, por lo que no ha sido muy aceptada.

- T2Candida es una prueba basada en PCR que utiliza resonancia magnética para detectar Candida spp. en sangre total. Aporta resultados pareados igual que la PNA-FISH. Después de procesada la sangre (lisis química y mecánica de eritrocitos), el resultado está disponible en 3-4 horas ${ }^{15}$. 
Según nuestros resultados, la PCR específica de especie mostró cuatro ventajas principales respecto al cultivo: 1) se obtuvo un $13 \%$ más de resultados positivos; 2) es un procedimiento rápido, pues desde que se recibe el espécimen hasta tener el resultado para las cuatro especies más comunes el tiempo invertido es de 6 horas, y el tiempo de espera de un cultivo es de 48-72 horas; 3 ) es posible detectar mezclas hasta de tres especies, mientras que con CHROMagar Candida $^{\text {TM }}$ se detectaron mezclas de dos especies; y 4) si bien el costo es más alto que el del cultivo (estimado en $\$ 560.00$ M.N., \$ 31.1 USD para las cuatro especies), este es bajo si se toma en cuenta el costo que implicaría una candidiasis invasiva no diagnosticada o mal tratada. Estas características fundamentan la propuesta de utilizar dicha técnica como un procedimiento que identifica al $80 \%$ de las especies causantes de candidiasis invasiva, enfermedad que en México no ha sido suficientemente explorada.

\section{Financiamiento}

Este trabajo fue realizado con el apoyo financiero de PAPIIT (Programa de Apoyo a Proyectos de Investigación e Innovación Tecnológica), de la Dirección General de Asuntos del Personal Académico, UNAM (Clave del Proyecto: IN224006).

José Luis Camacho Cardoso fue becario de CONACYT para este trabajo (Número de apoyo 205279).

María Ángeles Martínez Rivera es becaria EDI, COFAA, del Instituto Politécnico Nacional (IPN) y del Sistema Nacional de Investigadores (SNI), CONACYT.

\section{Agradecimientos}

A todas las personas que nos proporcionaron muestras clínicas: M. en C. Rocío López, del Hospital General Ignacio Zaragoza; I.S.S.S.T.E. M. en C. Alexandro Bonifaz, del Hospital General de México Dr. Eduardo Liceaga; y QBP. Rosa María Cervantes, del Hospital de Infectología, Centro Médico La Raza, IMSS.

\section{Bibliografía}

1. Linton CJ, Borman AM, Cheung G, et al. Molecular identification of unusual pathogenic yeast isolates by large ribosomal subunit gene sequencing: 2 years of experience at the United Kingdom mycology reference laboratory. J Clin Microbiol. 2007;45:1152-8.

2. Falagas ME, Roussos N, Vardakas KZ. Relative frequency of albicans and the various non-albicans Candida spp among candidemia isolates from inpatients in various parts of the world: a systematic review. Int $J$ Infect Dis. 2010;14: e954-66.

3. Aittakorpi A, Kuusela $P$, Koukila-Kahkola $P$, et al. Accurate and rapid identification of Candida spp. frequently associated with fungemia by using PCR and the microarray-based prove-it sepsis assay. J Clin Microbiol. 2012:50:3635-40
4. Sardi JSO, Scorzoni L, Bernardi T, et al. Candida species: current epidemiology, pathogenicity, biofilm formation, natural antifungal products and new therapeutic options. J Med Microbiol. 2013;62:10-24.

5. Armstrong-James D. Invasive Candida species infection: the importance of adequate empirical antifungal therapy. J Antimicrob Chemother. 2007;60:459-60.

6. Pfaller MA, Diekema DJ. Epidemiology of invasive candidiasis: a persistent public health problem. Clin Microbiol Rev. 2007;20:133-63.

7. Guinea J. Global trends in the distribution of Candida species causing candidemia. Clin Microbiol Infect. 2014;20:5-10.

8. Yapar N. Epidemiology and risk factors for invasive candidiasis. Ther Clin Risk Manag. 2014:10:95-105.

9. Estrada-Barraza D, Dávalos-Martínez A, Flores-Padilla L, et al. Comparación entre métodos convencionales, CHROMagar Candida y el método de la PCR para la identificación de especies de Candida en aislamientos clínicos. Rev Iberoam Micol. 2011;28:36-42.

10. Durán-Valle MT, Sanz-Rodríguez N, Muñoz-Paraíso C, et al. Identification of clinical yeasts by Vitek MS system compared with API ID $32 \mathrm{C}$. Med Mycol. 2014;52:342-9.

11. Pontón J. Utilidad de los marcadores biológicos en el diagnóstico de la candidiasis invasora. Rev Iberoam Micol. 2009;26:8-14.

12. Ellepola ANB, Morrison CJ. Laboratory diagnosis of invasive candidiasis. Microbiol. 2005;43:65-84

13. Pincus DH, Orenga S, Chatellier S. Yeast identification - past, present, and future methods. Med Mycol. 2007:45:97-121.

14. Lopes-Colombo A, Cortes JA, Zurita J, et al. Recommendations for the diagnosis of candidemia in Latin America. Rev Iberoam Micol. 2013; 30:150-7.

15. McCarty TP, Pappas PG. Invasive candidiasis. Infect Dis Clin North Am. 2016;30:103-24.

16. Luo G, Mitchell TG. Rapid identification of pathogenic fungi directly from cultures by using multiplex PCR. J Clin Microbiol. 2002:40:2860-5.

17. Buitrago MJ, Aguado JM, Ballen A, et al. Efficacy of DNA amplification in tissue biopsy samples to improve the detection of invasive fungal disease. Clin Microbiol Infect. 2012;19:E271-77.

18. Arvanitis M, Anagnostou T, Fuchs BB, et al. Molecular and nonmolecular diagnostic methods for invasive fungal infections. Clin Microbiol Rev. 2014;27:490-526.

19. Blin N, Stafford DW. A general method for isolation of high molecular weight DNA from eukaryotes. Nucleic Acids Res. 1976;3:2303-8.

20. Loffler J, Hebart H, Schumacher U, et al. Comparison of different methods for extraction of DNA of fungal pathogens from cultures and blood. J Clin Microbiol. 1997:35:3311-2.

21. Schabereiter-Gurtner C, Selitsch B, Rotter ML, et al. Development of novel real-time PCR assays for detection and differentiation of eleven medically important Aspergillus and Candida species in clinical specimens. J Clin Microbiol. 2007;45:906-14.

22. Guery BP, Arendrup MC, Auzinger G, et al. Management of invasive candidiasis and candidemia in adult non-neutropenic intensive care unit patients: part I. Epidemiology and diagnosis. Intensive Care Med. 2009;35:55-62.

23. Maaroufi Y, De Bruyne JM, Duchateau V, et al. Early detection and identification of commonly encountered Candida species from simulated blood cultures by using a real-time PCR-based assay. J Mol Diagnostics. 2004;6:108-14.

24. Filioti J, Spiroglou K, Roilides E. Invasive candidiasis in pediatric intensive care patients: epidemiology, risk factors, management, and outcome. Intensive Care Med. 2007:33:1272-83.

25. Méndez-Tovar LJ, Manzano-Gayosso P, Cumplido-Uribe C, et al. Micosis invasivas en pacientes inmunodeprimidos con fiebre de origen desconocido. Rev Med Inst Mex Seguro Soc. 2012;50:609-14.

26. Hernández-Hernández F, Córdova-Martínez E, Manzano-Gayosso P, et al. Frecuencia de micosis en pacientes inmunosuprimidos de un hospital regional de la Ciudad de México. Salud Publica Mex. 2003:45:455-60.

27. González GM, Elizondo M, Ayala J. Trends in species distribution and susceptibility of bloodstream isolates of Candida collected in Monterrey, Mexico, to seven antifungal agents: results of a 3-year (2004 to 2007) surveillance study. J Clin Microbiol. 2008:46:2902-5.

28. Philip A, Odabasi Z, Matiuzzi G, et al. Syscan3, a kit for detection of anti-Candida antibodies for diagnosis of invasive candidiasis. J Clin Microbiol. 2005:43:4834-5.

29. Lockhart SR, Iqbal N, Cleveland AA, et al. Species identification and antifungal susceptibility testing of Candida bloodstream isolates from population-based surveillance studies in two U. S. cities from 2008 to 2011. J Clin Microbiol. 2012;50:3435-42.

30. Quindós G. Epidemiology of candidaemia and invasive candidiasis. A changing face. Rev Iberoam Micol. 2014;31:42-8.

31. Manzano-Gayosso P, Méndez-Tovar LJ, Arenas R, et al. Levaduras causantes de onicomicosis en cuatro centros dermatológicos mexicanos y su sensibilidad antifúngica a compuestos azólicos. Rev Iberoam Micol. 2011;28:32-5.

32. Pfaller MA, Moet GJ, Messer SA, et al Candida bloodstream infections: comparison of species distributions and antifungal resistance patterns in community-onset and nosocomial isolates in the SENTRY antimicrobial surveillance program, 2008-2009. Antimicrob Agents Chemother. 2011;55:561-6. 